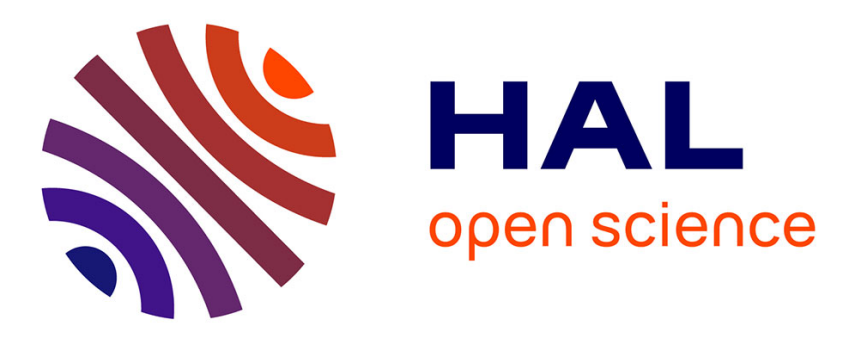

\title{
Dielectric properties of PDMS composites filled with SrTiO 3 nanoparticles
}

\author{
Povilas Bertasius, Sebastien Schaefer, Jan Macutkevic, Juras Banys, Algirdas \\ Selskis, Vanessa Fierro, Alain Celzard
}

\section{- To cite this version:}

Povilas Bertasius, Sebastien Schaefer, Jan Macutkevic, Juras Banys, Algirdas Selskis, et al.. Dielectric properties of PDMS composites filled with SrTiO 3 nanoparticles. Polymer Composites, 2021, 42 (6), pp.2982-2988. 10.1002/pc.26031 . hal-03407737

\section{HAL Id: hal-03407737 \\ https://hal.univ-lorraine.fr/hal-03407737}

Submitted on 28 Oct 2021

HAL is a multi-disciplinary open access archive for the deposit and dissemination of scientific research documents, whether they are published or not. The documents may come from teaching and research institutions in France or abroad, or from public or private research centers.
L'archive ouverte pluridisciplinaire HAL, est destinée au dépôt et à la diffusion de documents scientifiques de niveau recherche, publiés ou non, émanant des établissements d'enseignement et de recherche français ou étrangers, des laboratoires publics ou privés. 


\title{
Dielectric properties of PDMS composites filled with $\mathrm{SrTiO}_{3}$ nanoparticles
}

\author{
Povilas Bertasius $^{1}$, Sebastien Schaefer ${ }^{2}$, Jan Macutkevic ${ }^{1 *}$, Juras Banys ${ }^{1}$, Algirdas Selskis ${ }^{3}$, \\ Vanessa Fierro $^{2}$, Alain Celzard ${ }^{2}$ \\ ${ }^{1}$ Vilnius University, Sauletekio Ave. 3, Vilnius, Lithuania \\ ${ }^{2}$ Université de Lorraine, CNRS, IJL, 88000 Epinal, France \\ ${ }^{3}$ Center for Physical Science and Technology, Sauletekio Ave. 3, Vilnius, Lithuania \\ *jan.macutkevic@gmail.com
}

This paper deals with the dielectric properties of PDMS nanocomposites filled with $\mathrm{SrTiO}_{3}$ nanoparticles. The investigations were performed over a very broad range of frequencies $(20 \mathrm{~Hz}-3 \mathrm{THz})$. Almost no dielectric dispersion was observed in all the composites at room temperature over the entire range of measurement frequencies, and the dielectric losses were also very low under these conditions (less than 1.9). The dielectric dispersion was observed at lower temperatures (below $280 \mathrm{~K}$ ), due to relaxation at the $\mathrm{PDMS}_{\mathrm{SrTiO}}$ interface and in the bulk polymer. The relaxation time for both cases followed the Vogel-Vulcher law, while the freezing temperature was substantially lower for relaxation at the $\mathrm{PDMS}_{\mathrm{S}} \mathrm{SrTiO}_{3}$ interface.

$\mathrm{SrTiO}_{3}$, dielectric permittivity, polydimethylsiloxane

\section{INTRODUCTION}

New materials with special linear and non-linear dielectric properties are required in modern industry, people's life and environmental protection. For the progress of flexible electronics, new polymeric composite systems are desired [1]. Polydimethylsiloxane (PDMS) is a widely used elastic transparent polymer [2]. In addition, PDMS has excellent gas impermeability, biocompatibility, UV resistance, heat and oxidation stability, making it an important prospective matrix for polymer composites [3]. However, PDMS has low mechanical properties, low electrical conductivity and low dielectric permittivity values [3]. Nevertheless, these properties can be improved by the appropriate incorporation of nanoparticles [4-6]. PDMS composites are widely used in flexible bioelectronics, as sensors, coatings and batteries, and also for 3D-printing [7-9]. 
$\mathrm{SrTiO}_{3}$ is a well-known quantum paraelectric [10-11]. No ferroelectric phase transition occurs in this material down to the lowest temperatures, but the dielectric permittivity decreases sharply on cooling. Moreover, the main dielectric dispersion is observed in the terahertz and infrared frequency ranges, while at lower frequencies the dielectric permittivity is almost independent of the frequency. Therefore, it is applicable in various electronic fields where high dielectric permittivity and low dielectric losses are required over a broad frequency range. In particular, the dielectric tunability of $\mathrm{SrTiO}_{3}$ by electric field, light and temperature is observed at terahertz frequencies [12]. Therefore, it is possible to make various devices operating in the terahertz frequency range, such as high-speed electronic modulators, photonic crystals and metamaterials [13]. In electronics, $\mathrm{SrTiO}_{3}$ is also applicable as wide gap semiconductor with a bandgap of $3.2 \mathrm{eV}$.

$\mathrm{SrTiO}_{3}$ composites are widely investigated as cooling materials [14], for dielectric capacitors and energy storage applications [15], or for photocatalytic water splitting for hydrogen production [16]. The dielectric properties of $\mathrm{SrTiO}_{3}$ in various polymer matrices have been mainly investigated at low frequency $[17,18]$. It has been established that the dielectric permittivity of composites based on nano $\mathrm{SrTiO}_{3}$ can be quite high at room temperature (about 60 for polyethylene with $12 \%$ $\mathrm{SrTiO}_{3}$ of volume fraction) and is strongly dependent on the distribution of $\mathrm{SrTiO}_{3}$ particles in the polymer matrix, being more important for aggregated $\mathrm{SrTiO}_{3}$ particles [19]. It has also been shown that the dielectric relaxation in polymer composites with $\mathrm{SrTiO}_{3}$ particles is mainly due to polymerrelated relaxation and interfacial relaxation [20]. The dielectric properties of polymeric composites with $\mathrm{SrTiO}_{3}$ particles can be tuned by the electric field [20]. However, research on composites containing $\mathrm{SrTiO}_{3}$ nanoparticles in the microwave and terahertz frequency ranges is rather rare [21].

The objective of this paper was to study the dielectric properties of $\mathrm{SrTiO}_{3} / \mathrm{PDMS}$ composites in wide frequency (including microwave and terahertz frequency ranges) and temperature ranges (100-300 K, where PDMS is stable [18]). 


\section{EXPERIMENTAL}

$\mathrm{SrTiO}_{3}$ with particle sizes of $100 \mathrm{~nm}$ was purchased from US Research Nanomaterials, Inc (USA), while the PDMS matrix was purchased from Farnell (France) under the reference Sylgard 184 Silicone Elastomer (Dow Corning®).

Prior to any synthesis, PDMS was degassed under reduced pressure (4 $000 \mathrm{~Pa}, 30 \mathrm{~min}$ ) at room temperature. For each composite, the corresponding amount of $\mathrm{SrTiO}_{3}$ was dispersed in isopropanol (IPA) and under inert atmosphere $\left(\mathrm{N}_{2}\right)$ to avoid any potential oxidation of silver. The IPA-based suspension containing $\mathrm{SrTiO}_{3}$ nanoparticles was then sonicated for $3 \mathrm{~h}$ in an ultrasonic bath (VWR USC $1200 \mathrm{TH}, 600 \mathrm{~W}$ ), and for $5 \mathrm{~min}$ using a sonotrode (VWR DIGITAL, $450 \mathrm{~W}$, with a $13 \mathrm{~mm}$ diameter probe) at $20 \%$ of its maximum power. The suspension was then poured over the corresponding amount of PDMS and was then sonicated using the same procedure. In order to evaporate the IPA, the IPA/SrTiO $3 / \mathrm{PDMS}$ blend thus obtained was placed overnight in a ventilated oven at $60^{\circ} \mathrm{C}$. The resultant $\mathrm{PDMS} / \mathrm{SrTiO}_{3}$ paste was sonicated (ultrasonic bath) once more for $1.5 \mathrm{~h}$. The required amount of curing agent specified by the supplier was then added. The resultant mixture was then gently stirred by hand for $10 \mathrm{~min}$. In order to remove air bubbles that may have been trapped during this step, the final mixture was degassed under reduced pressure (4 $000 \mathrm{~Pa}, 2$ min). Depending on the viscosity of the final mixes, the composites were cast or manually pressed into moulds before curing. The composites were finally cured for $2-3 \mathrm{~h}$ at $90^{\circ} \mathrm{C}$ in a ventilated oven. Visually, the color of all investigated composites is white, they are not transparent in optical frequency range. Composites with 30 vol. $\% \mathrm{SrTiO}_{3}$ is flexible, while composites with bigger $\mathrm{SrTiO}_{3}$ concentrations are completely hard.

Scanning electron microscopy (SEM) images were obtained with a JSM 6460 LV electron microscope. Broadband measurements were performed using several techniques. At low frequencies (20 Hz - $1 \mathrm{MHz}$ ), the complex dielectric permittivity was obtained from the complex capacitance, which was measured by a HP4824 LCR meter. The measurements accuracy in this frequency range was better than $10 \%$. In the microwave frequency range, from $8 \mathrm{GHz}$ to $50 \mathrm{GHz}$, the reflectance and 
transmission of a thin dielectric rod placed inside a waveguide were studied. A custom-made waveguide spectrometer was used in this frequency range [22]. The typical value for the rod diameter was several hundred micrometres. The best measurements accuracy in this frequency range was in the middle of the band i.e. close to $30 \mathrm{GHz}$, in this case it is better than $10 \%$. In the terahertz frequency range (from $100 \mathrm{GHz}$ to $3 \mathrm{THz}$ ), a terahertz time domain spectrometer (Ekspla Ltd) based on a femtosecond laser was used for the measurements. The spectrometer is based on a femtosecond laser fibre (wavelength $1 \mu \mathrm{m}$, pulse duration less than $150 \mathrm{fs}$ ) and a GaBiAs photoconductive terahertz emitter and detector. The signal-to-noise ratio was as high as $60 \mathrm{~dB}$ at a frequency of $0.5 \mathrm{THz}$. The complex effective permittivity was calculated according to the Fresnel equation [23]:

$$
T(\omega)=\frac{4 N \exp \left(\frac{i \omega(N-1) d}{c}\right)}{(N+1)^{2}} \sum_{k=0}^{m}\left[\frac{\left(\frac{N-1}{N+1}\right) \exp (i \omega N d)}{c}\right]^{2 k},
$$

where $\mathrm{N}=\mathrm{n}-\mathrm{ik}=\left(\varepsilon^{*}\right)^{0.5}$ is the complex refractive index, $\varepsilon^{*}$ is the complex dielectric permittivity, $\mathrm{d}$ is the sample thickness, $\mathrm{c}$ is the light velocity and $\mathrm{m}$ labels number of reflections in the sample. These reflections are experimentally resolved and form separate pulses in the measured signal, so that the value of the coefficient $\mathrm{m}$ can be easily determined.

The measurement accuracy was better than $1 \%$ at frequency $0.5 \mathrm{THz}$ (where a signal to noise ratio is highest). At low frequencies $(20 \mathrm{~Hz}-1 \mathrm{MHz})$, the measurements were also performed in the temperature range of 100 to $300 \mathrm{~K}$. Silver paste was used to make electrical contacts with the samples. The real part $\sigma^{\prime}$ of the complex electrical conductivity was calculated as $\sigma^{\prime}=\omega \varepsilon_{0} \varepsilon^{\prime \prime}$, where $\omega$ is the angular frequency, $\varepsilon_{0}$ is the permittivity of vacuum, and $\varepsilon$ " is the imaginary part of the complex dielectric permittivity.

\section{RESULTS AND DISCUSSION}

SEM images of PDMS-based composite materials filled with $\mathrm{SrTiO}_{3}$ nanoparticles are presented in Fig. 1. The $\mathrm{SrTiO}_{3}$ nanoparticles were well dispersed in composites with different filler 
concentrations, as all areas studied in the composites with the same filler concentrations were similar.

The temperature dependence of complex dielectric permittivity for PDMS composites filled with 30 vol. $\% \mathrm{SrTiO}_{3}$ nanoparticles is presented in Fig. 2. The main dielectric anomaly was observed at about $175 \mathrm{~K}$. It is related to the glass transition ( $\alpha$ relaxation) in pure PDMS [24]. The $\alpha$ relaxation is due to a large-scale collective motion of many backbone segments in the amorphous phase of PDMS. The additional dielectric anomaly was clearly observed as the maximum of dielectric losses in the temperature range 200-250 K (depending on the measurements frequency) and the change in the slope of temperature dependence of the dielectric permittivity. The additional anomaly is related to the glass transition in the polymer-filler interface ( $\alpha$ ' relaxation) $[25,26]$. Both relaxations are related with the orientation polarization $[25,26]$. 

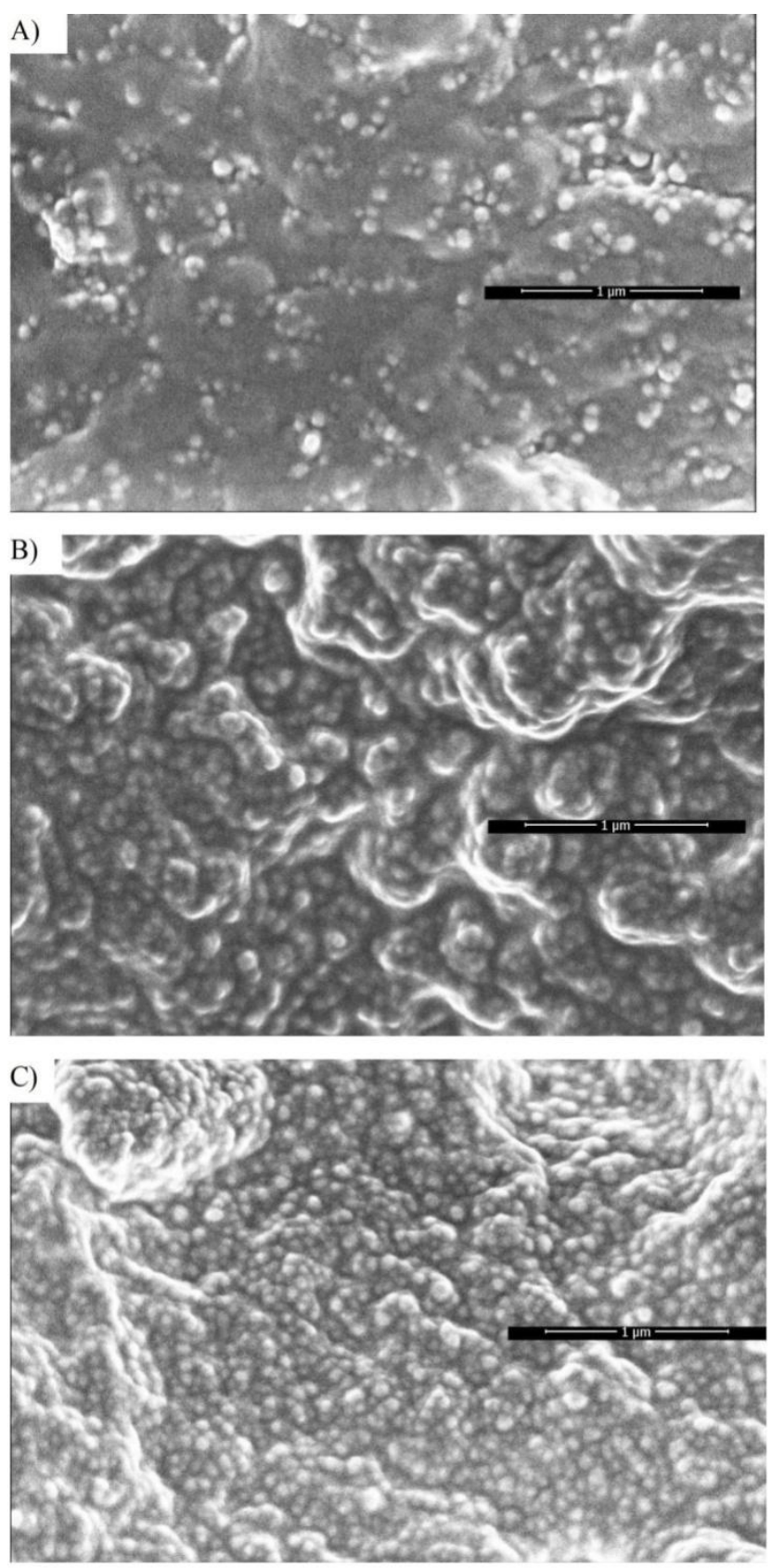

Fig. 1 SEM images of $\mathrm{SrTiO}_{3} / \mathrm{PDMS}$ composites of different volume fractions of $\mathrm{SrTiO}_{3}$ nanoparticles: A) 10 vol. \%; B) 30 vol. \%; C) 40 vol. \%.

Dielectric properties of pure PDMS and composites filled with $\mathrm{SrTiO}_{3}$ nanoparticles at low frequencies (not higher than $1 \mathrm{MHz}$ ) are quite similar. The difference is only in the appearance of dielectric dispersion related with $\alpha^{\prime}$ relaxation (which is related to the glass transition in polymer- 
filler interface) in $\mathrm{SrTiO}_{3} / \mathrm{PDMS}$ composites, the $\alpha^{\prime}$ relaxation is completely absent in pure PDMS. The $\alpha^{\prime}$ relaxation becomes stronger with increasing $\mathrm{SrTiO}_{3}$ concentration (will be shown below).
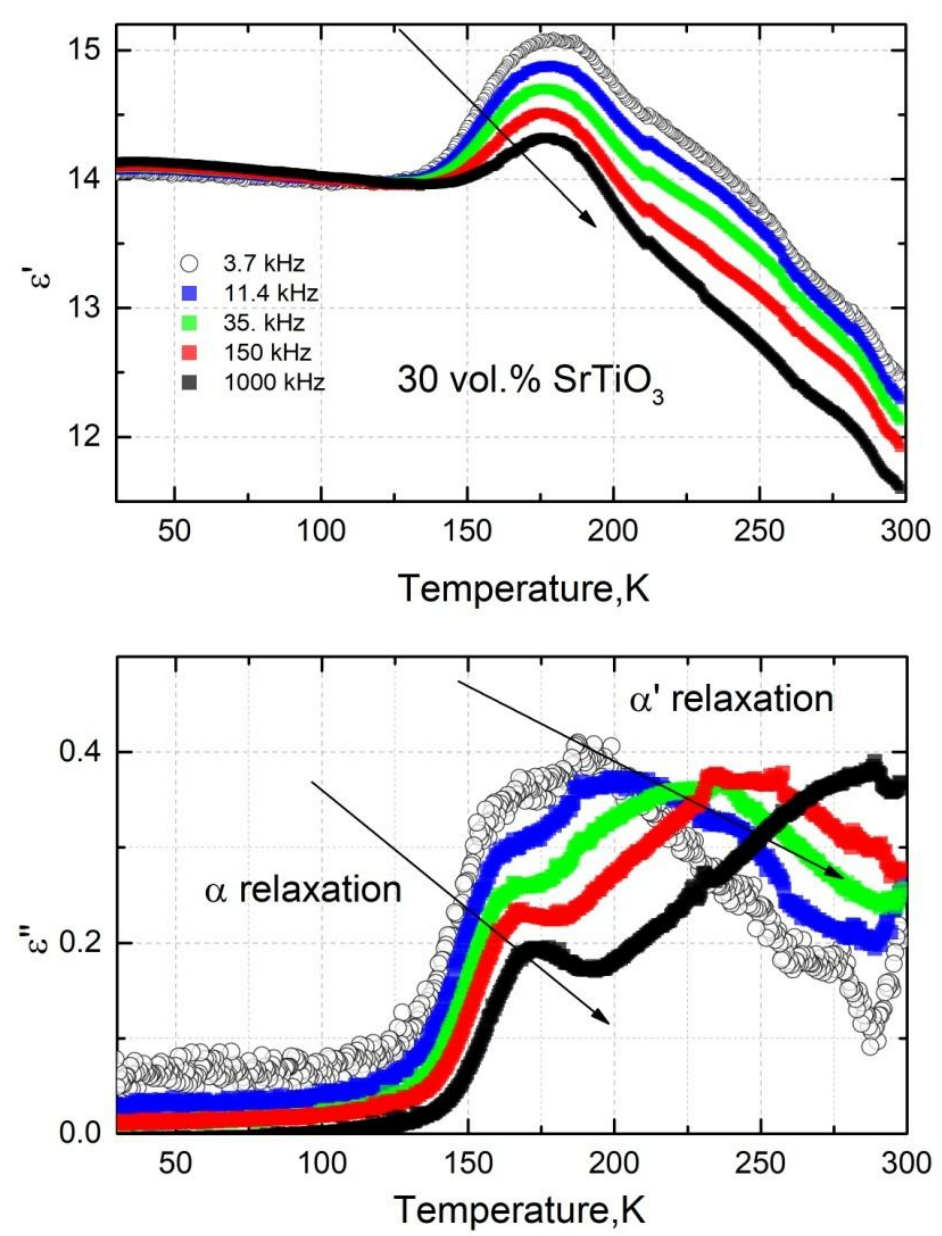

Fig. 2 Temperature dependence of the complex dielectric permittivity of PDMS composites filled with 30 vol.\% $\mathrm{SrTiO}_{3}$ nanoparticles. The arrow indicates the increase in the frequency at which the composites were studied.

The maxima of dielectric permittivity and losses as a function of temperature depend on the frequency. The frequency $v$ is plotted as a function of the maximum position of the dielectric losses for all investigated composites and pure PMMA in Fig. 3. It can be seen that the $\alpha^{\prime}$ relaxation appears in $\mathrm{SrTiO}_{3} / \mathrm{PDMS}$ composites, while the $\alpha$ relaxation disappears in composites with 50 vol.\% inclusions. The dependence was fitted with the Fogel-Vulcher law: 


$$
v=v_{0} e^{\frac{-E}{T-T_{0}}}
$$

where $k_{b}$ is the Boltzmann constant, $v_{0}$ is the attempt frequency and $T_{0}$ is the glass transition temperature of the polymer when the cooling rate becomes infinitely slow, $E$ is the activation energy .

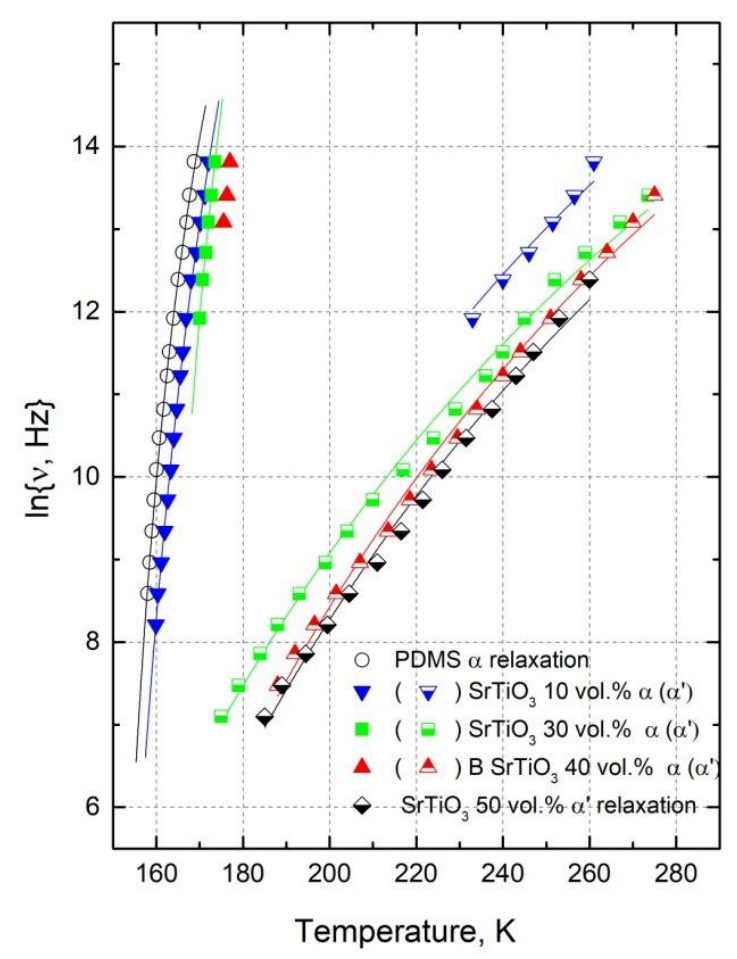

Fig. 3 Measurement frequency versus the temperature of dielectric losses maximum for $\mathrm{SrTiO}_{3} / \mathrm{PDMS}$ composites.

The parameters obtained are summarised in Table I. It can be seen that there is no clear dependence of $E$ and $T_{0}$ on concentration. However, the activation energy for $\alpha^{\prime}$ relaxation was substantially higher than the activation energy for $\alpha$ relaxation, while the freezing temperature was lowest for $\alpha$ relaxation.

Table I. Parameters of Vogel-Fulcher fit.

\begin{tabular}{|l|l|l|l|}
\hline & $\tau_{0}, \mathrm{ps}$ & $\mathrm{E}, \mathrm{K}$ & $\mathrm{T}_{0}, \mathrm{~K}$ \\
\hline 0 vol.\% $(\alpha$ relaxation $)$ & 0.03 & 343 & 135 \\
\hline
\end{tabular}




\begin{tabular}{|l|l|l|l|l|}
\hline \multirow{2}{*}{10 vol.\% } & $\alpha$ relaxation & 4.8 & 707 & 126 \\
\cline { 2 - 6 } & $\alpha^{6}$ relaxation & 0.53 & 3637 & 10 \\
\hline \multirow{2}{*}{30 vol.\% } & $\alpha$ relaxation & 0.24 & 331 & 147 \\
\cline { 2 - 5 } & $\alpha^{6}$ relaxation & 0.53 & 4358 & 43 \\
\hline 40 vol.\% ( $\alpha^{6}$ relaxation $)$ & 0.53 & 4054 & 18 \\
\hline 50 vol.\% $\left(\alpha^{6}\right.$ relaxation $)$ & 0.53 & 4311 & 30 \\
\hline
\end{tabular}

Two mechanisms have an impact on the freezing temperature in polymeric composites: the interaction between polymer molecules and nanoparticles increases the freezing temperature, while the appearance of free volume at the polymer/nanoparticle interface decreases the freezing temperature [27]. It can be concluded that both mechanisms are important in the composites under study. Moreover, the free spaces are located closer to the nanoparticles. Both relaxation mechanisms are related with orientation polarization.

The temperature dependence of the complex dielectric permittivity for all composites studied at the frequency of $3.7 \mathrm{kHz}$ is presented in Fig. 4.
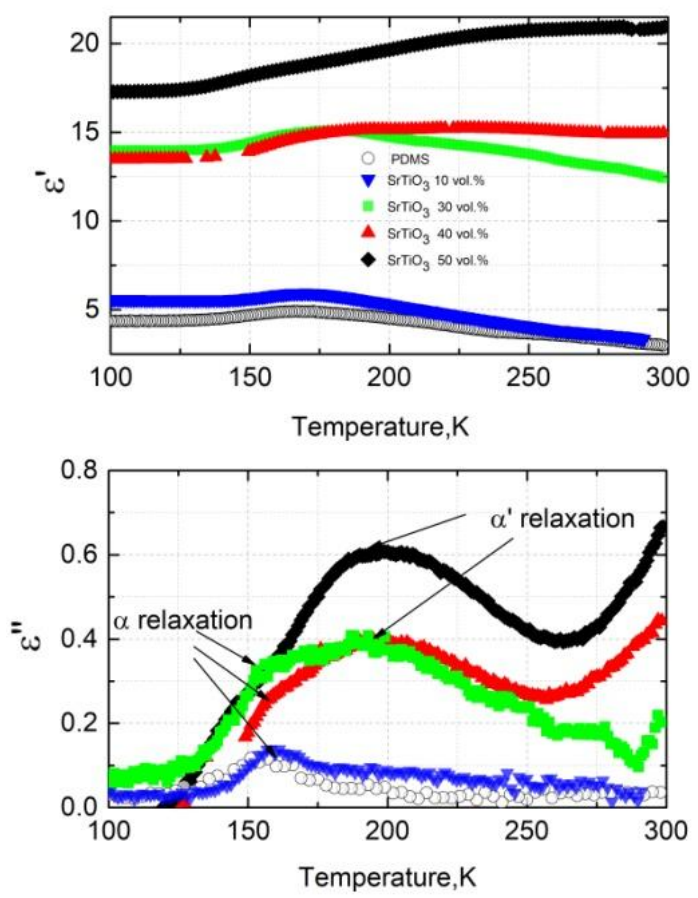

Fig. 4 Temperature dependence of the complex dielectric permittivity at $3.7 \mathrm{kHz}$ for $\mathrm{SrTiO}_{3} / \mathrm{PDMS}$ composites. 
It can be observed that both dielectric permittivity and dielectric losses strongly increased with the concentration of $\mathrm{SrTiO}_{3}$. The dielectric permittivity was high (about 20 at room temperature) for the composites with the highest $\mathrm{SrTiO}_{3}$ concentration, while the losses were low (less than 0.6). The increase of the dielectric permittivity with the $\mathrm{SrTiO}_{3}$ concentration is related with ionic polarization of $\mathrm{SrTiO}_{3}$ [18]. Moreover, it is possible from the data presented in $\mathrm{Fg}$. 4 to separate contributions of $\alpha$ and $\alpha^{\prime}$ relaxations. The $\alpha^{\prime}$ relaxation becomes stronger with increasing $\mathrm{SrTiO}_{3}$ concentration, while the $\alpha$ relaxation disappears in composites with $50 \mathrm{vol} . \%$. The small increase in dielectric losses with temperature at higher temperatures (above $270 \mathrm{~K}$ ) is related to the onset of electrical conductivity of $\mathrm{SrTiO}_{3}$ nanoparticles [28].
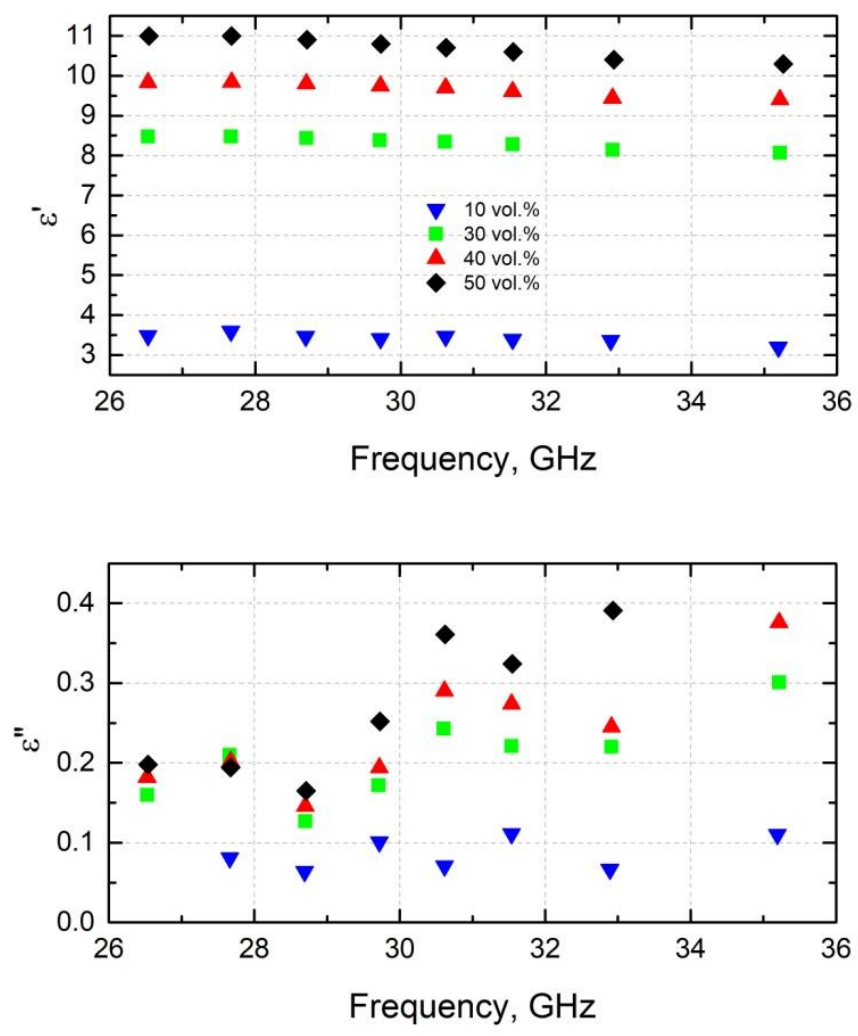

Fig. 5 Frequency dependence of complex dielectric permittivity in the microwave frequency range at room temperature for $\mathrm{SrTiO}_{3} / \mathrm{PDMS}$ composites. 
The dielectric permittivity of composites with the highest concentration of $\mathrm{SrTiO}_{3}$ was also high in the microwave frequency range, while the dielectric losses were low (Fig. 5). Moreover, the value of dielectric permittivity at $3.7 \mathrm{kHz}$ (Fig. 4) was almost equal to the value of dielectric permittivity at $39 \mathrm{GHz}$, indicating that the dielectric dispersion in the frequency range $3.7 \mathrm{kHz}-39$ $\mathrm{GHz}$ is very low. The small change of dielectric losses presented for composites with highest concentrations of $\mathrm{SrTiO}_{3}$ could be related with onset of $\mathrm{SrTiO}_{3}$ phonons, however these changes are very small and $\mathrm{SrTiO}_{3}$ phonon frequencies are observed usually in terahertz frequency range [12], so it will be further discussed below.

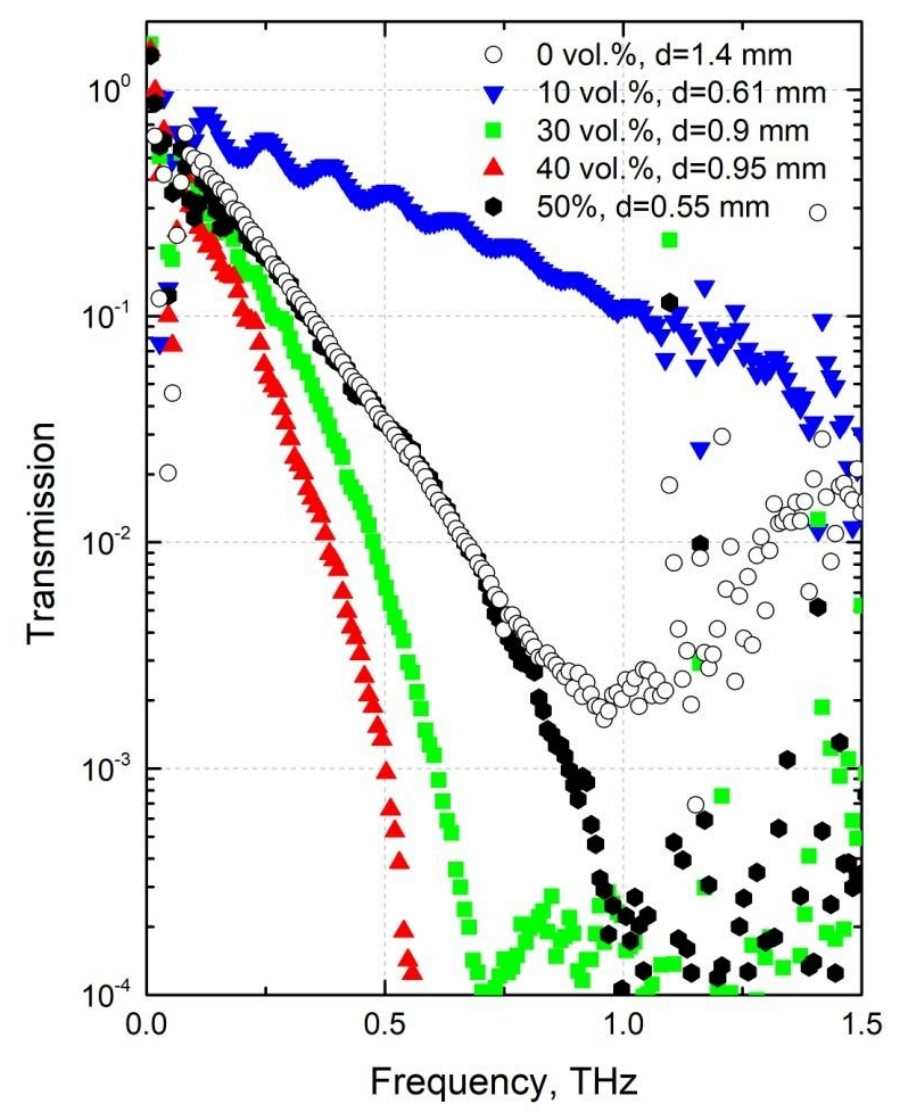

Fig. 6 Transmission spectra of $\mathrm{SrTiO}_{3} / \mathrm{PDMS}$ composites in the terahertz frequency range. The thickness of samples d is indicated in the legend. 
The transmission of composites in the terahertz frequency range decreased sharply with frequency up to a certain cut-off frequency, while at higher frequencies it was frequency-independent or even increased with frequency. The latter observation is rather an artefact related to the fact that the samples were opaque at these frequencies. The decrease in transmission with frequency in the terahertz frequency range can be explained by the decrease in complex dielectric permittivity with frequency or by the frequency-independent complex dielectric permittivity. It can be also mentioned, that the thickness of the sample has the strong impact on terahertz transmission (according to Eq. 1) and in possible composites applications, especially for 3D printing where small deviation on the expected thickness could happens [7], the sophisticated geometries can be printed.

The frequency dependence of the complex dielectric permittivity in the terahertz frequency range is presented in Fig. 7. As at lower frequencies, the complex dielectric permittivity increased with the concentration of $\mathrm{SrTiO}_{3}$. In composites containing $\mathrm{SrTiO}_{3}$ nanoparticles, the dielectric dispersion in the terahertz frequency range was very low and related to the onset of $\mathrm{SrTiO}_{3}$ phonons [12]. The high value of dielectric permittivity of the composites in the terahertz frequency range indicates that it can be changed by external parameters and that the composites are suitable for various flexible electronics components [13]. 

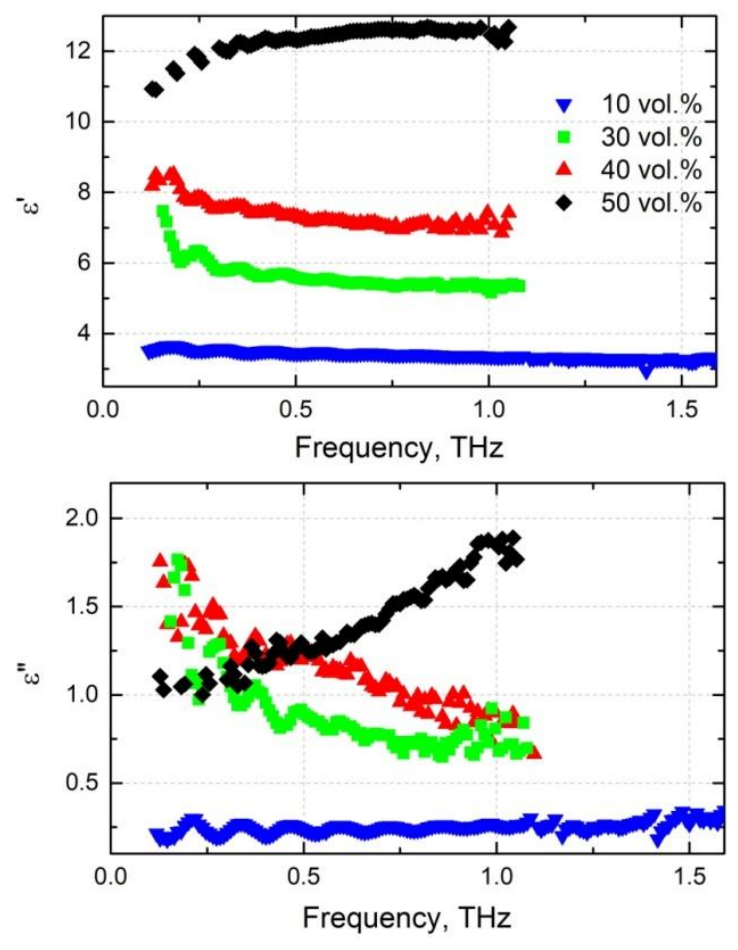

Fig. 7 Dielectric spectra of $\mathrm{SrTiO}_{3} / \mathrm{PDMS}$ composites in the terahertz frequency range.

\section{CONCLUSION}

Broadband investigations of PDMS composites filled with $\mathrm{SrTiO}_{3}$ nanoparticles were performed in a wide temperature range, from 100 to $300 \mathrm{~K}$. No dielectric dispersion was detected in the frequency range $20 \mathrm{~Hz}-2 \mathrm{THz}$ at room temperature. The dielectric losses under these conditions were very low (less than 1.8 ), while the dielectric permittivity was rather high (up to 20 for 50 vol. $\%$ composites). Therefore, these composites are suitable for various flexible electronic applications. The dielectric relaxation was only observed at lower temperatures (below $280 \mathrm{~K}$ ) and at lower frequencies (below $1 \mathrm{MHz}$ ). It results from a relatively large-scale cooperative motion of many backbone segments in the amorphous phase of PDMS in the bulk polymer and at the $\mathrm{PDMS} / \mathrm{SrTiO}_{3}$ interface. The freezing temperature was substantially lower in the $\mathrm{PDMS} / \mathrm{SrTiO}_{3}$ interface than in the bulk polymer volume, indicating that free spaces are mainly concentrated near the $\mathrm{SrTiO}_{3}$ nanoparticles. 


\section{REFERENCES}

[1] M. Kaltenbrubrunner, T. Sekitani, J. Reeder, T. Yokota, K. Kuribara, T. Tokuhara, M. Drack, R. Schwodiauer, I. Graz, S. Bauer-Gogonea, S, Bauer, T. Someya, Nature, 499, 458 (2013).

[2] S. H. Cho, H. M. Anderson, S. R. White, N. R. Sottos, P. V. Braun, Adv. Mater., 18, 997 (2006).

[3] A. Kausar, Polym.-Plast. Technol. Mater. 59, 1148 (2020).

[4] J. Su, L. Ju, A. L. Skov, Polym.-Plast. Technol. Mater. 59, 271 (2020).

[5] J. Macutkevic, I. Kranauskaite, J. Banys, S. Moseenkov, V. Kuznetsov, O. Shenderova, J. Appl. Phys. 115, 213702 (2014).

[6] N. Meng, M. Zhang, M. Q. Ge, N. Zhou, C. Chi, X. Chu, B. Sun, X. Gao, Polymer Composites 41, 1979-1985 (2020).

[7] T. A. Pham, T. K. Nguyen, R. Vadivelu, T. Dinh, A. Qamar, S. Yadav, Y. Yamauchi, J. A. Rogers, N. T. Nguyen, H. P. Pham, Adv. Funct. Mater., 2004655 (2020).

[8] D. K. Bharti, M. K. Gupta, R. Kumar, N. Sathish, A. K. Srivastava, Nano Energy 73, 104821 (2020).

[9] E. Palaimiene, S. Schaefer, J. Macutkevic, J.Banys, A. Selskis, V. Fierro, A. Celzard, Polymer Composites 41, 4750-4756 (2020).

[10] W. Zhong, D. Vanderbilt, Phys. Rev. B 53, 5047-5050 (1996).

[11] J. Hemberger, M. Nicklas, R. Viana, P. Lunkehemer, A. Loidl, R. Bohmer, J. Phys. Cond. Matter. 8, 4673-4690 (1996).

[12] P. Kuzel, F. Kadlec, H. Nemec, R. Ott, E. Hollmann, N. Klein, Appl. Phys. Lett. 88, 102901 (2006).

[13] P. Kuzel, F. Kadlec, C. R. Physique 9, 197-214 (2008).

[14] Z. Mao, Z. Yang, J. Zhang, Ceram. Int. 45, 16078-16087 (2019).

[15] N. Labhasetwar, G. Saravanan, S. K. Megarajan, N. Manwar, R. Khabragade, P. Doggali, F. Grasset, Sci. Technol. Adv. Mater. 16, 036002 (2015). 
[16] Z. Shen, J. Wang, X. Zhang, Y. Lin, C. Nan, L. Chen, Y. Shen, Appl. Phys. Lett. 111, 092901 (2017).

[17] J. Wang, S. Liu, J. Wang, H. Hao, L. Zhao, J. Zhai, J. Alloys. Compounds 726, 587-592 (2017).

[18] G. C. Manika, G. C. Psarras, J. Mater. Sci. Mater. 30, 13740-13748 (2019).

[19] Z. H. Shen, J. J. Wang, X. Zhang, Y. Lin, C. W. Nan, L. Q. Chen, Y. Shen, Appl. Phys. Lett. 111, 092901 (2017).

[20] G. C. Manika, G. C. Psarras, ACS Appl. Energy Mater. 3, 831-842 (2020).

[21] M. Murugan, M. S. Bapat, V. K. Kokate, J. Electromagn. Waves Appl. 30, 366-374 (2016).

[22] J. Grigas, Microwave dielectric spectroscopy of ferroelectric and related materials (Gordon and Science Publications, OPA, Amsterdam, 1996).

[23] I. Pupeza, R. Wilk, M. Koch, Opt. Express. 15, 4335 (2007).

[24] M. H. Youssef, Polym. Test. 22, 235 (2003).

[25] P. Klonos, A. Panagopolou, A. Kyritsis, L. Bokobza, P. Pissis, J. Non. Cryst. Solids 357, 610 (2011).

[26] D. Fragidakis, P. Pissis, J. Non. Cryst. Solids 353, 4344 (2007).

[27] J. Macutkevic, P. Kuzhir, A. Paddubskaya, S. Maksimenko, J. Banys, A. Celzard, V. Fierro, E. Stefanutti, A. Cataldo, F. Micciulla, S. Bellucci, J. Nanosci. Nanotechnol. 13, 5434 (2013).

[28] A. Mizera, E. Drozdz, Ceram. Int. 46, 24635 (2020). 